\title{
Solubilities and Major Species of Selenium and Technetium in the KURT Groundwater Conditions
}

\author{
KURT 지하수 조건에서 셀레늄과 테크네튬의 용해도 및 주요 화학종 \\ Seung Soo Kim1), Je Ho Min, Min Hoon Baik and Gye Nam Kim \\ Korea Atomic Energy Research Institute, 989-111 Daedeok-Daero, Yuseong-Gu, Daejeon \\ 김승수1), 민제호, 백민훈, 김계남 \\ *한국원자력연구원, 대전시 유성구 대덕대로 989번길 111
}

(Received November 21, 2011 / Received February 08, 2012 / Approved February 09, 2012)

\begin{abstract}
The long-lived fission products ${ }^{79} \mathrm{Se}$ and ${ }^{99} \mathrm{Tc}$ have been considered as the major concern nuclides for the disposal of radioactive waste because of their high solubilities and the existence of anionic species in natural water. In this study, the solubilities of $\mathrm{FeSe}_{2}(\mathrm{~s})$ and $\mathrm{TcO}_{2}(\mathrm{~s})$, known as respective Solubility Limiting Solid Phase (SLSP) of selenium and technetium, were measured in the KURT (KAERI Underground Research Tunnel) groundwater under various $\mathrm{pH}$ and redox conditions. And their solubilities and major species were also calculated using geochemical codes under conditions similar to experimental solutions. Experimental results and calculation for $\mathrm{FeSe}_{2}$ show that the solubility of selenium was found to be below $1 \times 10^{-6} \mathrm{~mol} / \mathrm{L}$ under the condition of $\mathrm{pH} 8 \sim 9.5$ and $\mathrm{Eh}=-0.3 \sim$ $-0.4 \mathrm{~V}$ while the dominant species was identified as $\mathrm{HSe}^{-}$. For $\mathrm{TcO}_{2}$, the solubility of technetium was found to be $5 \times 10^{-8} \sim 1 \times 10^{-9} \mathrm{~mol} / \mathrm{L}$ in the solutions of $\mathrm{pH} 6 \sim 9.5$ and Eh<-0.1 V, while the dominant species was $\mathrm{TcO}(\mathrm{OH})_{2}$. However, when the Eh of the solution is $-0.35 \mathrm{~V}, \mathrm{TcO}(\mathrm{OH})_{3}{ }^{-}$and $\mathrm{TcO}_{4}{ }^{-}$are calculated as the dominant species at $\mathrm{pH} 10.5 \sim 12$ and $\mathrm{pH}>12$, respectively.
\end{abstract}

Key words : Selenium, Technetium, Solubility, Species, Groundwater

\section{요 약}

장수명 핵분열생성물인 ${ }^{79} \mathrm{Se}$ 와 ${ }^{99} \mathrm{Tc}$ 는 자연수 중에서 용해도가 클 뿐더러 음이온으로 존재하여 방사성폐 기물 처분장에서 주요 관심핵종들로 고려되고 있다. 본 연구에서는 KURT 지하수의 다양한 $\mathrm{pH}$ 와 산화-환 원 조건에서 셀레늄과 테크네튬의 Solubility Limiting Solid Phase (SLSP)로 알려진 $\mathrm{FeSe}_{2}$ 와 $\mathrm{TcO}_{2}$ 의 용해 도를 측정하였다. 또한, 지화학코드를 이용하여 실험과 유사조건에서 이들의 용해도와 주요 화학종을 계 산하였다. 실험 및 계산으로부터 $\mathrm{pH}$ 8 9.5와 $\mathrm{Eh}=-0.3 \sim-0.4 \mathrm{~V}$ 조건에서 $\mathrm{FeSe}_{2}$ 의 용해도는 $1 \times 10^{-6} \mathrm{~mol} / \mathrm{L}$ 이하이며, 주 용해 화학종은 $\mathrm{HSe}$-로 판단된다. $\mathrm{TCO}_{2}$ 의 경우는 $\mathrm{pH}$ 6 9.5와 $\mathrm{Eh}\langle-0.1 \mathrm{~V}$ 영역에서 용해도와 주 용해 화학종이 각각 $5 \times 10^{-8} \sim 1 \times 10^{-9} \mathrm{~mol} / \mathrm{L}$ 와 $\mathrm{TCO}(\mathrm{OH})_{2}$ 로 나타났지만, $\mathrm{Eh}=-0.35 \mathrm{~V}$ 조건에서는 주 용해

1) Corresponding Author. E-mail : nsskim@kaeri.re.kr 
화학종이 $\mathrm{pH}$ 가 $10.5 \sim 12$ 와 12 이상에서 각각 $\mathrm{TcO}(\mathrm{OH})_{3}{ }^{-}$와 $\mathrm{TcO}_{4}{ }^{-}$로 계산되었다.

중심단어 : 셀레늄, 테크네튬, 용해도, 화학종, 지하수

\section{I. 서 론}

핵분열생성물 중 ${ }^{79} \mathrm{Se}$ 와 ${ }^{99} \mathrm{Tc}$ 는 반감기가 각각 $3.6 \times 10^{5}$, $2.1 \times 10^{5}$ 년으로 장수명 핵종이다. 이들 원소는 자연수 중에서 용해도가 클 뿐더러 지하수 환경에서 음이온으로 존재하여 처분장 주변 암석에 잘 흡착하지 않을 것으로 예상되어, 방사 성폐기물 처분장에서 주요 관심핵종들로 고려되고 있다 $[1,2]$.

셀레늄은 환원조건에서 $\mathrm{Se}(\mathrm{IV}), \mathrm{Se}(0), \mathrm{Se}(\mathrm{II})$ 로 존재하는 것으로 알려져 있다. 그러나 일반 화강암심부지하조건 $(\mathrm{pH}=8.5 \sim 9.5, \mathrm{Eh} \leq-0.35 \mathrm{~V})$ 을 고려할 경우, Se(IV)의 양은 미 미할 뿐더러 철 부식물에도 쉽게 흡착하는 것으로 알려져 있 다[3, 4]. 한편, $\mathrm{Se}(\mathrm{cr})$ 는 환원조건의 증류수에 $10^{-5} \sim 10^{-6}$ $\mathrm{mol} / \mathrm{L}$ 정도 용해되는 것으로 발표되었다[5]. $\mathrm{Se}(\mathrm{cr})$ 이 환원조 건에서 지하수를 만나면 아래 반응식과 같이 hydrogen selenide (HSe')로 용해된다[6].

$$
\mathrm{Se}(s) \rightarrow H S e^{-}-H^{+}-2 e^{-}
$$

생성된 $H S e^{-}$는 염기성 용액에서 아래 식과 같이 polyselenide $\left(\mathrm{Se}_{4}^{2-}\right)$ 를 형성할 수 있는데, 이 $\mathrm{Se}_{4}^{2-}$ 는 음이온으 로 처분장의 암반이나 벤토나이트에 흡착되기 어렵다[5].

$$
4 \mathrm{HSe}^{-} \rightarrow 4 \mathrm{H}^{+}-6 e^{-} \rightarrow \mathrm{Se}_{4}{ }^{2-}
$$

고준위폐기물 처분장에서 셀레늄의 용해도를 좌우하는 고 체상 (Solubility Limiting Solid Phase, SLSP)으로는 Se(cr), $\mathrm{FeSe}_{2}, \mathrm{FeSe}$ 등이 예상되는데, 특히 $\mathrm{FeSe}_{2}$ 가 많이 고려되고 있 다 $[7,8]$. 이 경우 셀레늄과 철의 화합물은 지하수 중의 철이나 처분용기로부터 유출된 철 이온과의 반응을 고려한 것이다.

테크네튬은 자연수 중에서 $\mathrm{TCO}_{4}^{-}$로 존재하는데, 이 $\mathrm{TcO}_{4}^{-}$ 는 환원성 지하수에서 $\mathrm{Tc}(\mathrm{IV})$ 로 환원될 수 있다. $\mathrm{Tc}(\mathrm{IV})$ 는 용 해도가 낮고, 주변 매질과 흡착되기 쉬워 처분장에서 이동성 이 낮을 수도 있다. 심부지하 처분조건에서 테크네튬의 SLSP 로는 $\mathrm{TCO}_{2}$ 가 알려져 있다[9, 10].

본 연구에서는 KAERI Underground Research Tunnel (KURT) 지하수에 환원제를 첨가하여 산화환원 전위를 조절 한 상태에서 $\mathrm{FeSe}_{2}, \mathrm{TcO}_{2}$ 의 용해도를 각각 측정하였다. 또한,
실험과 유사한 조건에서 지화학코드를 이용하여 용해도를 계 산하였으며, 문헌값과도 상호 비교하였다. 또한, 이 지화학코 드를 이용하여 셀레늄과 테크네튬의 용해되어 있는 화학종도 계산하였다.

\section{II, 실험 및 계산}

\section{가. 시약 및 장비}

셀레늄의 용해도 측정을 위하여 $\mathrm{FeSe}_{2}$ 를 다음과 같이 합성 하였다[11].

(1) $\mathrm{FeCl}_{3} \cdot 6 \mathrm{H}_{2} \mathrm{O}, \mathrm{Na}_{2} \mathrm{SeO}_{3}$, hydrazine hydrate $\left(\mathrm{N}_{2} \mathrm{H}_{4} \cdot \mathrm{H}_{2} \mathrm{O}\right)$ 의 농도가 각각 $0.075,0.075,1.5 \mathrm{~mol} / \mathrm{L}$ 이 되도록 혼합하여 증류수 $40 \mathrm{~mL}$ 에 교반하면서 녹인다.

(2) 이 혼합액을 $100 \mathrm{~mL}$ 테프론 코팅된 스테인리스 autoclave 병에 넣고, $140^{\circ} \mathrm{C}$ 에서 12 시간동안 반응시킨다.

(3) 용기를 식혀 생성된 검정색 생성물 $\mathrm{FeSe}_{2}$ 를 증류수와 에 탄올로 서너 차례 세척한 후, $50^{\circ} \mathrm{C}$ 진공오븐에서 6시간 이상 건조시킨다.

(4) 건조된 $\mathrm{FeSe}_{2}$ 의 일부를 X-ray Diffractometer (XRD, Bruker, D5000)로 확인하였으며 (Fig. 1), 글러브박스(M.O. Tech, 국산)에 보관하였다.

$\mathrm{TcO}_{2}$ 의 용해도를 측정하기 위하여 Eckert \& Ziegler Isotope Products로부터 구매한 ammonium pertechnetate를 아래 순 서와 같이 아연분말로 환원시켜 $\mathrm{TCO}_{2}$ 를 제조하였다[12].

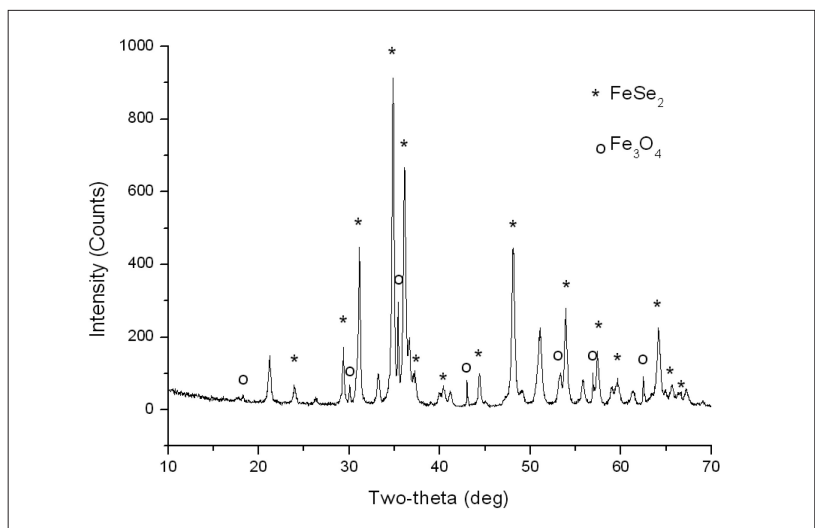

Fig. 1. XRD pattern of synthesized $\mathrm{FeSe}_{2}$. 
(1) 유리병에 증류수 $15 \mathrm{~mL}$ 와 고순도 염산 2 3 $\mathrm{mL}$ 를 넣고 용액을 $40^{\circ} \mathrm{C}$ 로 유지한다.

(2) 용액에 약 $8 \mathrm{mg}$ 의 테크네튬에 해당하는 ammonium pertechnetate를 넣는다.

(3) 용액온도를 $40^{\circ} \mathrm{C}$ 로 유지한 상태에서 아연분말을 수 $\mathrm{mg}$ 첨가한다.

(4) 모든 아연이 반응한 다음, 진한 암모니아수를 가하여 용 액의 $\mathrm{pH}$ 를 5.5 6.0으로 조절한다. 만약, $\mathrm{pH}$ 가 6.0보다 높으 면 아연수산화물 침전이 형성된다.

(6) 검정색의 수화된 $\mathrm{TcO}_{2}$ 가 생성된다.

(7) $40^{\circ} \mathrm{C}$ 로 용액을 20 분간 유지시켜 검정색 분말을 충분히 생성시킨다.

(8) $3000 \mathrm{rpm}$ 으로 5 분간 원심분리한 다음, 상등액을 버린다.

(9) 검정색 분말을 글러브박스에서 건조시킨다.

실험에 사용한 지하수는 KURT DB-1 시추공에서 지하 약 $200 \mathrm{~m}$ 깊이의 지하수를 패커시스템을 사용하여 채취하였다. 지하수 보관용기로는 $20 \mathrm{~L}$ 테프론 코팅된 스테인리스 용기를 사용하였으며, 지하수 채취 전에 용기 내부를 고순도 (>99.999\%) 질소로 10분 이상 흘려주었고, 질소로 충전된 상 태에서 지하수를 포집하였다. 사용한 KURT 지하수의 조성을 Table 1에 나타내었는데, 주로 Inductively Coupled PlasmaMass Spectrometry (ICP-MS, Perkin-Elmer, Elan 6100)와 Ion Chromatography (IC, Dionex사 DX-500)를 사용하여 분석하 였다. 채취한 지하수는 냉장보관하였다.

용액중 셀레늄의 농도는 ICP-MS로, 테크네튬의 선량은 Liquid Scintillation Counter (LSC, Packard, Tri-Carb $2770 \mathrm{TR} / \mathrm{SL}$ )로 측정하였다.

\section{나. 용해도 측정 실험}

KURT 지하수의 산화환원 전위를 조절하기 위하여 KURT 지하수 $30 \mathrm{~mL}$ 에 환원제인 hydrazine의 농도가 10, 1.0, 0.1

Table 1. Composition of KURT groundwater.

\begin{tabular}{|c|c|c|c|}
\hline Element & $\begin{array}{c}\text { Concentration } \\
(\mathrm{mg} / \mathrm{L})\end{array}$ & Element & $\begin{array}{c}\text { Concentration } \\
(\mathrm{mg} / \mathrm{L})\end{array}$ \\
\hline $\mathrm{Na}$ & 19.9 & $\mathrm{Sr}$ & $5.8 \times 10^{-4}$ \\
\hline $\mathrm{K}$ & 0.6 & $\mathrm{Al}$ & $3.7 \times 10^{-2}$ \\
\hline $\mathrm{Ca}$ & 13.9 & $\mathrm{~W}$ & $8.6 \times 10^{-3}$ \\
\hline $\mathrm{Mg}$ & 1.5 & $\mathrm{Fe}$ & $2.0 \times 10^{-2}$ \\
\hline $\mathrm{CO}_{3}+\mathrm{HCO}_{3}$ & 83 & $\mathrm{Ba}$ & $8.0 \times 10^{-2}$ \\
\hline $\mathrm{Cl}_{4}$ & 2.1 & $\mathrm{Mo}$ & $6.0 \times 10^{-2}$ \\
\hline $\mathrm{SO}_{4}$ & 18.8 & $\mathrm{~B}$ & $7.0 \times 10^{-4}$ \\
\hline $\mathrm{NO}_{3}$ & 0.2 & $\mathrm{Zn}$ & $1.5 \times 10^{-2}$ \\
\hline $\mathrm{F}$ & 3.8 & $\mathrm{Li}$ & $2.4 \times 10^{-2}$ \\
\hline $\mathrm{Si}$ & 18.8 & $\mathrm{Cu}$ & $3.0 \times 10^{-3}$ \\
\hline $\mathrm{Mn}$ & $1.3 \times 10^{-2}$ & & \\
\hline $\mathrm{pH}$ & 8.1 & $\mathrm{Eh}$ & $-200 \mathrm{mV}$ \\
\hline
\end{tabular}

$\mathrm{mmol} / \mathrm{L}$ 되도록 $1 \mathrm{~mol} / \mathrm{L}$ hydrazine 용액을 첨가한 후, 이들 용 액 각각에 $0.2 \mathrm{~g}$ 의 $\mathrm{FeSe}_{2}$ 를 넣고 상온 $\left(\right.$ 약 $20^{\circ} \mathrm{C}$ )에서 용해도 실 험을 실시하였다. $12,26,35$ 일 경과한 다음, 상등액을 채취하 여 공극크기 $0.22 \mu \mathrm{m}$ polyethersulfone (PES) 필터로 여과하 였으며, 이들 중 몇 용액은 NMWL (Nominal Molecular Weight Unit) 1000 의 ultrafiltration membrane (Millipore, $\mathrm{PES}$ 로 여과하였다. 처분조건에서 테크네틈 농도 예측을 위해 서는 $\mathrm{FeSe}_{2}$ 대신에 $0.015 \mathrm{~g}$ 의 $\mathrm{TcO}_{2}$ 를 넣고 동일한 방법으로 시 도하였다. 여과된 시료용액은 시료용기벽에 테크네튬의 흡착 을 막기 위하여 고순도 질산 $20 \mu \mathrm{L}$ 를 적가한 후 분석하였다.

\section{다. 지화학코드를 이용한 용해도 및 화학종 계산}

실험과 유사한 $\mathrm{pH}$ 와 Eh값을 갖는 KURT 지하수 조건에서 PHREEQC와 MINTEQ 지화학코드를 사용하여 셀레늄과 테 그네튬의 용해도와 주요 용해 화학종을 계산하였다. 또한, 심 부지하수의 산화환원 전위를 $\mathrm{Eh}=-0.35 \mathrm{~V}$ 로 고정시킨 상태에 서 $\mathrm{pH}$ 및 핵종 농도에 따른 주요 화학종의 분포를 Visual MINTEQ 코드로 계산하였다. 계산에 사용된 셀레늄과 테그네 튬의 반응식 및 평형상수를 각각 Table 2와 Table 3 에 나타내

Table 2. Reactions and equilibrium constants of selenium used for the calculation of solubility and major species.

\begin{tabular}{|c|c|}
\hline Reaction & log $\mathrm{Ka}$ \\
\hline $\mathrm{Se}^{2-}+\mathrm{H}^{+}=\mathrm{HSe}^{-}$ & 14.9 \\
\hline $2 \mathrm{Se}^{2-}=\mathrm{Se}_{2}{ }^{--}+2 \mathrm{e}^{-}$ & 25.32 \\
\hline $3 \mathrm{Se}^{2-}=\mathrm{Se}_{3}{ }^{--}+4 \mathrm{e}^{-}$ & 49.966 \\
\hline $\mathrm{HSe}^{-}+4 \mathrm{H}_{2} \mathrm{O}=\mathrm{SeO}_{4}{ }^{2-}+9 \mathrm{H}^{+}+8 \mathrm{e}^{-}$ & -81.13 \\
\hline $\mathrm{HSe}^{-}+\mathrm{H}^{+}=\mathrm{H}_{2} \mathrm{Se}(\mathrm{aq})$ & 3.8 \\
\hline $4 \mathrm{HSe}^{-}=\mathrm{Se}_{4}{ }^{2-}+4 \mathrm{H}^{+}+6 \mathrm{e}^{-}$ & 14.4 \\
\hline $\mathrm{HSe}^{-}+3 \mathrm{H}_{2} \mathrm{O}=\mathrm{SeO}_{3}{ }^{--}+7 \mathrm{H}^{+}+6 \mathrm{e}^{-}$ & -45.64 \\
\hline $\mathrm{H}_{2} \mathrm{Se}^{+} 3 \mathrm{H}_{2} \mathrm{O}=\mathrm{H}_{2} \mathrm{SeO}_{3}+6 \mathrm{H}^{+}+6 \mathrm{e}^{-}$ & -46.2 \\
\hline $\mathrm{SeO}_{3}{ }^{2-}+\mathrm{H}^{+}=\mathrm{HSeO}_{3}{ }^{-}$ & 8.36 \\
\hline $\mathrm{SeO}_{3}{ }^{-}+\mathrm{H}_{2} \mathrm{O}=\mathrm{SeO}_{4}{ }^{-}+2 \mathrm{H}^{+}+2 \mathrm{e}^{-}$ & -27.49 \\
\hline $\mathrm{SeO}_{3}{ }^{--}+2 \mathrm{H}^{+}=\mathrm{H}_{2} \mathrm{SeO}_{3}$ & 11.24 \\
\hline $\mathrm{SeO}_{4}{ }^{2-}+2 \mathrm{H}^{+}=\mathrm{H}_{2} \mathrm{SeO}_{4}$ & -0.21 \\
\hline $\mathrm{HSeO}_{4}{ }^{-}=\mathrm{SeO}_{4}{ }^{2-}+\mathrm{H}^{+}$ & -1.75 \\
\hline $\mathrm{H}_{2} \mathrm{SeO}_{3}=\mathrm{HSeO}_{3}{ }^{-}+\mathrm{H}^{+}$ & -2.64 \\
\hline $\mathrm{H}_{2} \mathrm{SeO}_{3}+\mathrm{H}_{2} \mathrm{O}=\mathrm{HSeO}_{4}{ }^{-}+3 \mathrm{H}^{+}+2 \mathrm{e}^{-}$ & -37.3 \\
\hline $2 \mathrm{HSe}^{-}+\mathrm{Fe}^{+}=\mathrm{FeSe}_{2}(\mathrm{~s})+2 \mathrm{H}^{+}+2 \mathrm{e}^{-}$ & 16.8 \\
\hline
\end{tabular}

a All data refer to a standard state $(298.15 \mathrm{~K}, 0.1 \mathrm{MPa}$ and ionic strength $=0)$.

Table 3. Reactions and equilibrium constants of technetium used for the calculation of solubility and major species.

\begin{tabular}{|c|c|}
\hline Reaction & $\log \mathrm{Ka}$ \\
\hline $\mathrm{TcO}(\mathrm{OH})_{2}+\mathrm{H}^{+}=\mathrm{H}_{2} \mathrm{O}+\mathrm{TcO}(\mathrm{OH})^{+}$ & 2.5 \\
\hline $\mathrm{TcO}(\mathrm{OH})_{2}+2 \mathrm{H}^{+}=\mathrm{TcO}_{2}{ }^{+}+2 \mathrm{H}_{2} \mathrm{O}$ & 3.87 \\
\hline $\mathrm{TcO}_{2}{ }^{+}+3 \mathrm{H}_{2} \mathrm{O}=3 \mathrm{H}^{+}+\mathrm{TcO}(\mathrm{OH})_{3}{ }^{-}$ & -14.9 \\
\hline $\mathrm{TcO}_{2}{ }^{+}+\mathrm{CO}_{3}{ }^{2-}+\mathrm{H}_{2} \mathrm{O}=\mathrm{TcCO}_{3}(\mathrm{OH})_{2}$ & 15.25 \\
\hline $\mathrm{TcO}_{2}{ }^{+}+\mathrm{CO}_{3}{ }^{2-}+2 \mathrm{H}_{2} \mathrm{O}=\mathrm{TcCO}_{3}(\mathrm{OH})_{3}^{-}+\mathrm{H}^{+}$ & 6.95 \\
\hline $\mathrm{TcO}_{2}{ }^{+}+3 \mathrm{H}_{2} \mathrm{O}=\mathrm{TcO}_{4}^{-}+6 \mathrm{H}^{+}+3 \mathrm{e}^{-}$ & -33.43 \\
\hline $\mathrm{TcO}_{2} \cdot 1.6 \mathrm{H}_{2} \mathrm{O}(\mathrm{s})+2 \mathrm{H}^{+}=\mathrm{TcO}_{2}{ }^{+}+2.6 \mathrm{H}_{2} \mathrm{O}$ & 4.4 \\
\hline
\end{tabular}

a All data refer to a standard state (298.15 K, 0.1 MPa and ionic strength $=0)$. 
었는데, 이 데이터는 OECD/NEA[9, 13], Nagra/PSI[14], $\mathrm{JAEA}[15]$, 그리고 $\mathrm{SKB}[6]$ 보고서들에서 수집하였다. 모든 용 해도 및 화학종은 $25^{\circ} \mathrm{C}$ 조건에서 계산하였다.

\section{III. 결과 및 토의}

\section{가. 셀레늄}

Hydrazine을 이용하여 KURT 지하수의 산화환원 전위 를 조절한 용액에 $\mathrm{FeSe}_{2}$ 를 넣고 실험한 용해도 실험결과 를 Table 4에 수록하였다. 또한, 실험과 유사한 $\mathrm{pH}, \mathrm{Eh}$ 조건에서 PHREEQC와 MINTEQ 지화학코드를 사용하여 계산한 용해도 및 주 용해 화학종, 그리고 문헌에 발표된 셀레늄의 용해도 자료도 이 표에 추가하였다. 예상대로 두 코드로 계산한 용해도와 화학종은 매우 유사하게 나타 났다.

당 실험실에서 $-0.3 \mathrm{~V}$ 용액에 $\mathrm{FeSe}_{2}$ 를 넣고 $12,26,35$ 일 경과한 후 공극크기 $0.22 \mu \mathrm{m}$ 필터로 여과한 셀레늄의 농 도는 각각 $6 \times 10^{-8}, 1 \times 10^{-7}, 1.1 \times 10^{-7} \mathrm{~mol} / \mathrm{L}$ 로 측정되었다. 이 값들은 지화학코드로 계산한 값에 비하여 100 1000배 더 높게 나타났다. 그러나 이러한 용해도 차이는 Table 4 에 서 보는 바와 같이 외국의 유사한 조성을 갖는 지하수에서 도 발견되었다. 이러한 현상은 셀레늄의 용해도가 산화환 원전위에 매우 민감하므로 실험조건에 따라 큰 값 차이를 나타내는 것으로 생각된다. SKB-CEN에서는 $\mathrm{FeSe}$ 가 산화

Table 4. The solubilities of selenium in this study and literatures.

\begin{tabular}{|c|c|c|c|c|}
\hline Eh (V) & $\mathrm{pH}$ & $\begin{array}{l}\text { Solubility } \\
(\mathrm{mol} / \mathrm{L})\end{array}$ & $\begin{array}{l}\text { Dominant } \\
\text { species }\end{array}$ & Remarks \\
\hline-0.28 & 9.9 & $1.0 \times 10^{-7}$ & & \multirow{3}{*}{$\begin{array}{l}\text { Experimentally measured } \\
\text { values in this study }\end{array}$} \\
\hline-0 & 7.37 & $1.7 \times 10^{-4}$ & & \\
\hline+0.4 & 7.1 & $1.5 \times 10^{-3}$ & & \\
\hline-0.28 & 9.9 & $1.7 \times 10^{-10}$ & $\mathrm{HSe}^{-}$ & \multirow{5}{*}{$\begin{array}{c}\text { Calculated results by } \\
\text { PHREEQC and MINTEQ } \\
\text { in this study }\end{array}$} \\
\hline-0.34 & 9.9 & $1.6 \times 10^{-9}$ & $\mathrm{HSe}^{-}$ & \\
\hline-0.3 & 9.5 & $6.5 \times 10^{-10}$ & $\mathrm{HSe}^{-}$ & \\
\hline-0.4 & 9.5 & $3.0 \times 10^{-8}$ & $\mathrm{HSe}^{-}$ & \\
\hline-0 & 7.37 & $4.5 \times 10^{-7}$ & $\operatorname{Se}(0)$ & \\
\hline Oxidizing & & High & $\mathrm{SeO}_{3}^{2-}, \mathrm{SeO}_{4}^{2-}$ & References $[7,17,19]$ \\
\hline-0.28 & 8 & $1 \times 10^{-16}$ & $\mathrm{HSe}^{-}$ & Reference [19] \\
\hline-0.28 & 8.5 & $5 \times 10^{-9}$ & $\mathrm{HSe}^{-}$ & Reference [17], SLSP ${ }^{\mathrm{b}}=\mathrm{FeSe}_{2}$ \\
\hline-0.3 & 11.4 & $1 \times 10^{-7}$ & $\mathrm{HSe}^{-}$ & Reference [17], SLSP ${ }^{\mathrm{b}}=\mathrm{FeSe}_{2}$ \\
\hline-0.18 & 7.66 & $1.0 \times 10^{-8}\left(6.0 \times 10^{-7}\right)^{\mathrm{a}}$ & $\mathrm{HSe}^{-}$ & Reference [8], $\mathrm{SLSP}^{\mathrm{b}}=\mathrm{FeSe}_{2}$ \\
\hline $\begin{array}{l}-0.23 \sim \\
-0.06 \\
\end{array}$ & $7 \sim 8.5$ & $1.0 \times 10^{-8}$ & & $\begin{array}{c}\text { Reference [8] } \\
\text { (High-salinity groundwater) }\end{array}$ \\
\hline-0.35 & 7.8 & $4 \times 10^{-6}$ & $\mathrm{HSe}^{-}$ & Reference [8], SLSP ${ }^{\mathrm{b}}=\mathrm{Se}(\mathrm{s})$ \\
\hline-0.28 & 8.74 & $\left(8.0 \times 10^{-7}\right)^{\mathrm{a}}$ & $\mathrm{HSe}^{-}$ & Reference [8], SLSP ${ }^{\mathrm{b}}=\mathrm{FeSe}_{2}$ \\
\hline-0.2 & 6.9 & $1.0 \times 10^{-9}$ & $\mathrm{HSe}^{-}$ & Reference [8], SLSP ${ }^{\mathrm{b}}=\mathrm{Fe} 3 \mathrm{Se}_{4}$ \\
\hline-0.3 & 8.2 & $3.0 \times 10^{-8}$ & $\mathrm{HSe}^{-}$ & Reference [8], SLSP ${ }^{b}=\operatorname{Se}(\mathrm{s})$ \\
\hline-0.25 & & $5 \times 10^{-8}$ & $\mathrm{HSe}^{-}$ & $\begin{array}{l}\text { Reference [16], SLSP }{ }^{\mathrm{b}}=\text { FeSe } \\
\text { (Boom clay water) }\end{array}$ \\
\hline
\end{tabular}

a Conservative values in parentheses

b Solubility Limiting Solid Phase
에 매우 민감하므로 정밀한 세척이 필요하다고 주장하였다 [16]. 실제로 산화분위기, 즉 대기중에서 측정한 셀레늄의 농도를 외국의 경우 'high'로 표시하였다. 당 실험실에서 대기와 접한 KURT지하수에 7일간 $\mathrm{FeSe}_{2}$ 분말을 넣고 여과 하여 얻은 결과는 $1.5 \times 10^{-3} \mathrm{~mol} / \mathrm{L}$ 로 높게 나타났다. 따라서 실측값, 계산값과 문헌값을 비교해 볼 때, $\mathrm{pH}$ 가 7 10이 고, $\mathrm{Eh}$ 값이 $-0.3 \mathrm{~V}$ 부근의 환원 지하수에서 $\mathrm{FeSe}_{2}$ 의 용 해도는 대체로 $1 \times 10^{-7} \mathrm{~mol} / \mathrm{L}$ (보수적으로는 $1 \times 10^{-6} \mathrm{~mol} / \mathrm{L}$ ) 이하의 값을 갖는 반면, 산화조건에서는 $1 \times 10^{-3} \mathrm{~mol} / \mathrm{L}$ 이 상의 값을 갖는 것으로 판단된다. 지화학코드로 계산한 값 에서 $\mathrm{pH}$ 9.9와 9.5의 경우, $\mathrm{Eh}$ 의 값이 $-0.28 \sim-0.4 \mathrm{~V}$ 영역 에서 $\mathrm{Eh}$ 의 값이 소량 감소함에 따라 용해도가 증가하였다. 이러한 현상은 이 Eh 영역에서 용해도를 좌우하는 주 용해 화학종인 $\mathrm{HSe}^{-}$가 되기 위해서는 전자를 받아들여 $\mathrm{Se}(-\mathrm{II})$ 를 형성해야 하므로, $\mathrm{Eh}$ 의 값이 소량 낮은 용액에서 $\mathrm{HSe}^{-}$의 농도가 증가하기도 하는 것으로 생각된다. 또한, $\mathrm{pH}$ 가 12 이상의 강염기 용액에서는 $1 \times 10^{-6} \mathrm{~mol} / \mathrm{L}$ 이상으로 용해도 가 증가하는 것으로 보고되고 있다[17]. 철이 없는 증류수 에서 검정색 $\mathrm{Se}(\mathrm{cr})$ 을 이용하여 용해도를 측정한 결과는 $\mathrm{pH} 8.7, \mathrm{Eh}=-0.43 \mathrm{~V}$ 에서 $1.5 \times 10^{-7} \mathrm{~mol} / \mathrm{L}$ 의 셀레늄 농도를 얻었다.

KURT 지하수 조성 및 $\mathrm{Eh}=-0.35 \mathrm{~V}$ 조건에서 $\mathrm{pH}$ 에 따라 셀 레늄의 화학종을 계산한 결과를 Fig. 2에 나타내었다. 이 지 하수에는 철이 약 $4 \times 10^{-7} \mathrm{~mol} / \mathrm{L}$ 용해되어 있는데, $\mathrm{Eh}=-0.35 \mathrm{~V}$ 조건에서는 철이온이 $\mathrm{Fe}(\mathrm{II})$ 로 존재할 것이다. 이 $\mathrm{Fe}(\mathrm{II})$ 은 셀레늄 이온과 만나면 난용성 $\mathrm{FeSe}_{2}$ 를 형성한다. Fig. 2(a) 에서 $\mathrm{Se}_{4}{ }^{2-}$ 는 철 농도가 셀레늠 농도에 비해 낮아 $\mathrm{FeSe}_{2}$ 를 형 성하고 남은 셀레늄으로 인해 계산된 것이다. 하지만 Fig. 2(b)와 Fig. 2(c)와 같이 $4 \times 10^{-7} \mathrm{~mol} / \mathrm{L}$ 이하의 셀레늄 농도에 서는 모든 셀레늄이 알칼리 영역에서 $\mathrm{Se}_{4}{ }^{2-}$ 가 형성되지 않고 $\mathrm{FeSe}_{2}$ 를 형성하였다. 실제 자연수나 지하수 중 셀레늄의 농 도가 $10^{-8} \mathrm{~mol} / \mathrm{L}$ 이하로 매우 낮을뿐더러[18], 처분장에서도 셀레늄의 농도가 낮을 것으로 예상된다. 또한, 방사성폐기 물 처분장에서 처분용기의 부식에 의해 철의 농도는 매우 높을 것이다. 따라서 용해도 실험 및 화학종 계산에 사용한 $\mathrm{Fe}-\mathrm{Se}$ 화합물이 처분장에서 셀레늄 농도를 좌우할 것으로 판단된다.

\section{나. 테크네튬}

당 실험실에서 hydrazine을 첨가한 지하수에 $\mathrm{TcO}_{2}$ 를 넣 고 $12,26,35$ 일 경과한 후, $0.22 \mu \mathrm{m}$ 필터로 여과한 테크네 틈의 농도는 12 일 이후 $2.5 \times 10^{-8} \sim 5.0 \times 10^{-8} \mathrm{~mol} / \mathrm{L}$ 영역에서 

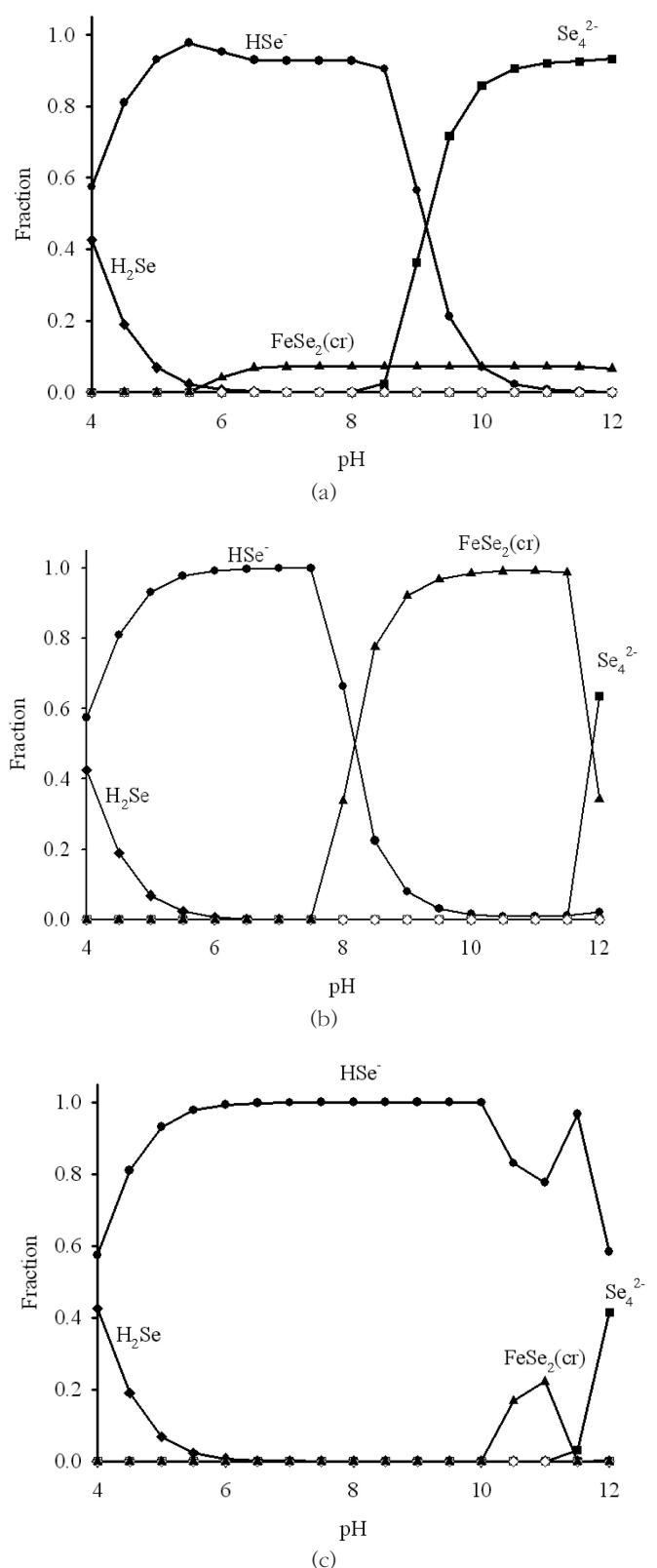

Fig. 2 Major species of selenium in KURT groundwater at Eh= $-0.35 \mathrm{~V}$. The species were calculated with a Visual MINTEQ code: (a) $[\mathrm{Se}]_{\text {total }}=10^{-5} \mathrm{~mol} / \mathrm{L},(\mathrm{b})[\mathrm{Se}]$ total $=10^{-7} \mathrm{~mol} / \mathrm{L}$ and $(\mathrm{c})[\mathrm{Se}]_{\text {total }}=$ $10^{-9} \mathrm{~mol} / \mathrm{L}$.

매우 안정된 값을 나타내었다. 환원전위가 $\mathrm{Eh}=-0.2 \sim-0.4 \mathrm{~V}$ 조건에서 얻은 본 실험결과를 Fig. 3에 타문헌값들과 같이 비교하였다. 이 그림에서 보는 바와 같이 중성 및 약염기 영 역 ( $\mathrm{pH}$ 6 9)에서 $\mathrm{Eh}$ 가 -0.1 V 이하인 용액에서 $\mathrm{TCO}_{2}$ 의 용 해도는 $5 \times 10^{-8} \sim 1 \times 10^{-9} \mathrm{~mol} / \mathrm{L}$ 로 나타났다. $\mathrm{TCO}_{2}$ 는 수용액 중에서 $\mathrm{TcO}_{2} \cdot \mathrm{xH}_{2} \mathrm{O}$ 로 수화되는데, 최근연구는 $\mathrm{x}$ 의 값이 약 1.6을 갖는다[6, 9]. 한편, 테크네튬의 용해도는 중성 및 약 염기 조건에서 산화환원전위가 $\mathrm{Tc}(\mathrm{IV})$ 를 유지할 경우, 지하

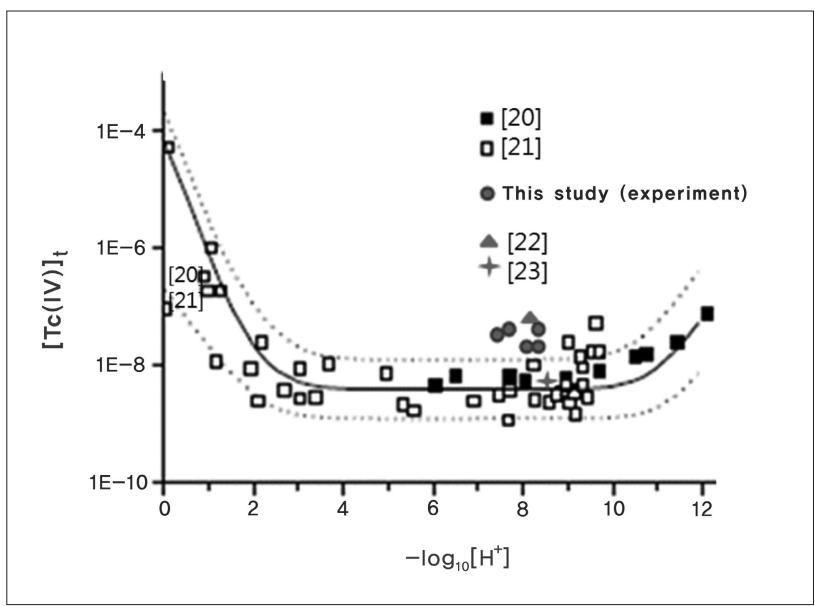

Fig. 3. Solubilities of technetium in the reducing groundwaters.

수의 조성 및 $\mathrm{pH}$ 의 영향을 크게 받지 않는 것으로 알려져 있다[6].

Visual MINTEQ 코드를 이용하여 Eh=-0.35 V 조건에서 테 크네튬의 농도에 따른 용액중 화학종들의 분포와 $\mathrm{TcO}_{2}$. $1.6 \mathrm{H}_{2} \mathrm{O}(\mathrm{s})$ 의 데이터를 이용하여 용해도를 계산한 결과를 각 각 Fig. 4 와 Fig. 5에 나타내었다. 이 그림들로부터 KURT와 같이 중성 및 약염기 영역의 $\mathrm{pH}$ 를 갖는 화강암 지하수의 경 우, 주 용해 화학종이 $\mathrm{TCO}(\mathrm{OH})_{2}$ 로 예상되며, $\mathrm{pH} 10.5$ 이상에 서는 $\mathrm{TcO}(\mathrm{OH})_{3}{ }^{-}$로 나타났다. 그러나 용액중 $\mathrm{pH}$ 가 12 이상의 강염기 용액에서는 $\mathrm{TcO}_{4}^{-}$가 주 용해 화학종으로 나타났는데, 이는 $\mathrm{TCO}_{4}^{-}$가 $\mathrm{Tc}(\mathrm{IV})$ 로 환원되는 전위가 매우 낮아서 테크네 튬이 $\mathrm{Tc}(\mathrm{VII})$ 로 존재하여 용해도가 증가하는 것으로 알려져 있다[6]. Fig. 5에 나타낸 KURT 지하수에서 계산한 테크네튬 의 용해도는 실험치보다 약간 낮았으나, 1 승수 이내에서 일 치하였다.

\section{IV. 결 론}

Eh의 값이 낮은 심부 지하수에서 셀레늄의 주요 거동은 철의 농도에 좌우될 것이며, KURT 지하수 성분에서 $\mathrm{FeSe}_{2}$ 의 용해도는 Eh값이 $-0.3 \mathrm{~V}$ 이하에서 $1 \times 10^{-6} \mathrm{~mol} / \mathrm{L}$ 이하의 값을 갖는 반면, 산화조건에서는 $1.0 \times 10^{-3} \mathrm{~mol} / \mathrm{L}$ 이상으로 판단된다. 환원 조건에서 주 용해 화학종은 $\mathrm{HSe}^{-}$로 계산되 었다.

$\mathrm{pH}$ 가 6 9.5 영역인 환원성 화강암지하수에서 $\mathrm{TCO}_{2}$ 의 용 해도는 $5 \times 10^{-8} \sim 1 \times 10^{-9} \mathrm{~mol} / \mathrm{L}$ 로 나타났으며, 이 $\mathrm{pH}$ 영역에 서 주 용해 화학종이 $\mathrm{TcO}(\mathrm{OH})_{2}$ 로 예상되지만, $\mathrm{pH} 10.5 \sim 12$ 와 $\mathrm{pH} 12$ 이상에서는 $\mathrm{TcO}(\mathrm{OH})_{3}{ }^{-}$와 $\mathrm{TcO}_{4}{ }^{-}$가 각각 주 용해 화학종으로 나타났다. 


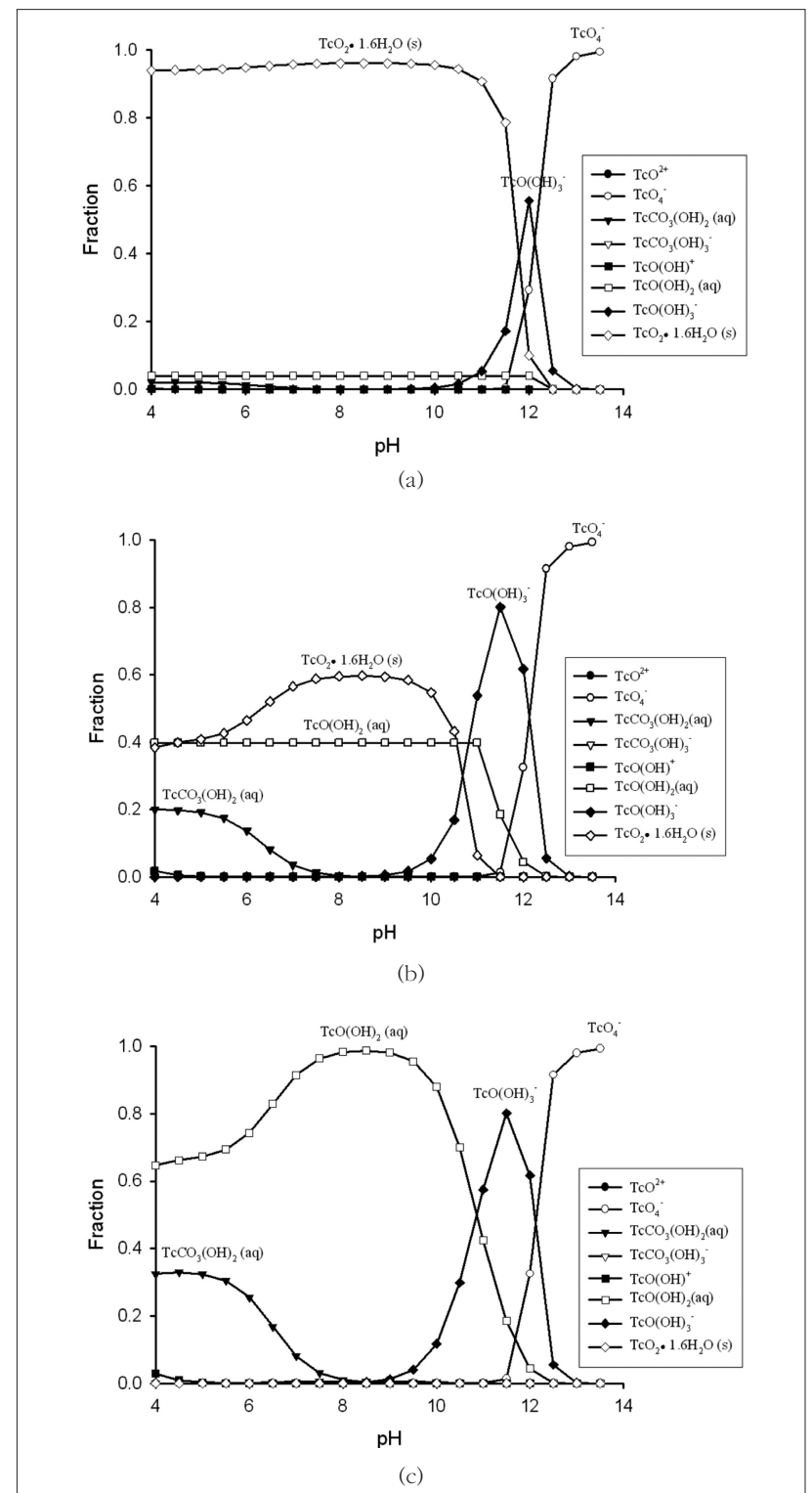

Fig. 4. Major technetium species in the KURT groundwater at $E h=-0.35 \mathrm{~V}$. The species were calculated with a Visual MINTEQ code: (a) $[\mathrm{Tc}]$ total $=10^{-7} \mathrm{~mol} / \mathrm{L},(\mathrm{b})[\mathrm{Tc}]$ total $=10^{-8} \mathrm{~mol} / \mathrm{L}$ and $(\mathrm{c})$ $\left[\right.$ Tc] total $=10^{-9} \mathrm{~mol}$.

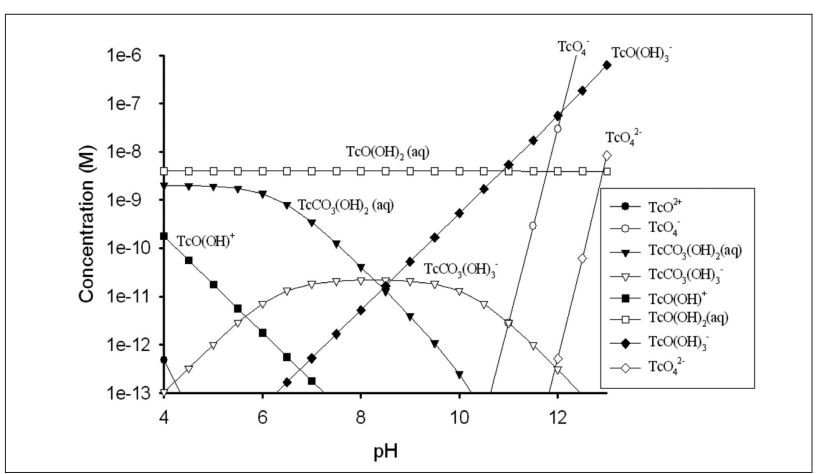

Fig. 5. Major technetium species and solubilities of $\mathrm{TcO}_{2} \cdot 1.6 \mathrm{H}_{2} \mathrm{O}$ in KURT groundwater at $\mathrm{Eh}=-\mathbf{0 . 3 5} \mathrm{V}$.

\section{감사의 글}

본 연구는 교육과학기술부가 주관하는 원자력중장기 연구 의 일환으로 수행되었습니다.

\section{References}

[1] Min-Hoon Baik, Jae-kwang Lee and Jong-Won Choi, "Research Status on the Radionuclide and Colloid Migration in Underground," Journal of the Korean Radioactive Waste Society, 7(4), pp. 243253 (2009).

[2] Y. S. Hwang and C. H. Kang, "The Development of a Safety Assessment Approach and Its Implication on the Advanced Nuclear Fuel Cycle," Nucl. Eng. Technol., 42(1), pp. 37-46 (2010).

[3] A.C. Scheinost, R. Kirsch, D. Banerjee, A. Fernandez-Martinez, H. Zaenker, H. Funke and L. Charlet, "X-ray Absorption and Photoelectron Spectroscopy Investigation of Selenite Reduction by Fe(II)-bearing Minerals," Contaminant Hydrology, 102, pp. 228-245 (2008).

[4] M. Rovira, J. Gim?nez, M. Martinez, X. MartinezLlado, J. de Pablo and V. Marti, "Sorption of Selenium(IV) and Selenium(VI) onto Natural Iron Oxides: Goethite and Hematite," J. Hazardous Materials, 150, pp. 279-284 (2007).

[5] Y. Iida, T. Yamaguchi, T. Tanaka and S. Nakayama, "Solubility of Selenium at High Ionic Strength under Anoxic Conditions," J. Nucl. Sci. Tech., 47(5), pp. 431-438 (2010).

[6] L. Duro, M. Grivé, E. Cera, C. Domènech and J. Bruno, Update of a Thermodynamic Database for Radionuclides to Assist Solubility Limits Calculation for Performance Assessment, SKB-TR-06-17 (2006).

[7] P. Toulhoat, "Confinement and Migration of Radionuclides in a Nuclear Waste Deep Repository," Applied Physics, C. R. Physique, 3, pp. 975-986 (2002).

[8] I. G. McKinley and D. Savage, "Comparison of Solubility Databases Used for HLW Performance 
Assessment," J. Contaminant Hydrology, 21, pp. 335-350 (1996).

[9] J. A. Rard, M. H. Rand, G. Anderegg and H. Wanner, Chemical Thermodynamics of Technetium, NEA/OECD, Elsevier, Amsterdam, The Netherlands (1999).

[10] Chang-Woo Lee, Kun-Ho Chung, Young-Hyun Cho, Mun-Ja Kang, Wanno Lee, Hee-Reyoung Kim and Geun Sik Choi, "Analysis of 99Tc and Its Activity Level in the Korean Soil," Journal of the Korean Radioactive Waste Society, 7(1), pp. 25-31 (2009).

[11] A. Liu, X. Chen, Z. Zhang, Y. Jiang and C. Shi, "Selective Synthesis and Magnetic Properties of $\mathrm{FeSe}_{2}$ and $\mathrm{FeTe}_{2}$ Nanocrystallites Obtained Through a Hydrothermal Co-reduction Route," Solid State Communications, 138, pp. 538-541 (2006).

[12] N. J. Pilkington, "The Solubility of Technetium in the Near-Field Environmental of Radioactive Waste Repository," J. Less-Common Met., 161, pp. 203212 (1990).

[13] A. Olin, B. Nolang, E. G. Osadchii, L. O. Ohman and E. Rosen, Chemical Thermodynamics of Selenium, NEA-TDB, OECD, North Holland Elsevier Science Publishers (2005).

[14] W. Hummel, U. Berner, E. Curti, F. J. Pearson and T. Thoenen, Nagra/PSI Chemical Thermodynamic Data Base 01/01, Universal Publishers, Florida, USA (2002).

[15] JAEA tdb, Japan Nuclear Cycle Development Institute (JNC), Waste Management and Fuel Cycle Research Center, Copyright 2003-2004. DATABASE Version : 011213c2.tdb.

[16] P. D. Cannière, A. Maes, S. Williams, C. Bruggeman, T. Beauwens, N. Maes and M. Cowper, Behaviour of Selenium in Boom Clay, SCK-CEN, Belgium, SCK-CEN-ER-120 (2010).

[17] M. Mihara, Radio-Nuclide Migration Databases (RAMDA) for the Safety Assessment of TRU Waste Repositories in Japan, Japan Atomic Energy Agency, JAEA-review 2006-011 (2006).

[18] V. Chand and S. Prasad, "Trace Determination and
Chemical Speciation of Selenium in Environmental Water Samples Using Catalytic Kinetic Spectrophotometric Method," J. Hazardous Materials, 165, pp. 780-788 (2009).

[19] J. H. Rees, "The Theoretical Derivation of Solubilities of Long-Lived Radionuclides in Disposal," J. Nucl. Mater. 130, pp. 336-345 (1985).

[20] T. E. Eriksen, P. Ndalamba, J. Bruno and M. Caceci, "The Solubility of $\mathrm{TcO}_{2} \mathrm{nH}_{2} \mathrm{O}$ in Neutral to Alkaline Solutions under Constant $\mathrm{pCO}_{2}$," Radiochim. Acta, 58/59, pp. 67-70 (1992).

[21] R. E. Meyer, W. D. Arnold, F. I. Case and G. D. O’Kelley, "Solubilities of Technetium(IV) Oxides," Radiochimica Acta, 55, pp. 19-22 (1991).

[22] T. Vieno and H. Nordman, Safety Assessment of Spent Fuel Disposal in Hastholmen, Kivetty, Olkiluoto and Romuvaara, TILA-99, Helsinki, Finland: POSIVA OY, POSIVA 99-07 (1999).

[23] R. T. Pabalan, D. R. Turner and M. P. Miklas, "Technetium-99 Chemistry in Reducing Groundwaters: Implications for the Performance of a Proposed High-Level Nuclear Waste Repository at Yucca Mountain, Nevada," Scientific Basis for Nuclear Waste Management XXIII, pp. 231-236. Warrendale, Pennsylvania: Materials Research Society (1999). 